University of Montana

ScholarWorks at University of Montana

2005

\title{
The Promise and Threat of Nanotechnology: Can Environmental Ethics Guide Us?
}

Christopher J. Preston

The University Of Montana, christopher.preston@mso.umt.edu

Follow this and additional works at: https://scholarworks.umt.edu/philosophy_pubs

Part of the Philosophy Commons

Let us know how access to this document benefits you.

\section{Recommended Citation}

Preston, Christopher J., "The Promise and Threat of Nanotechnology: Can Environmental Ethics Guide Us?" (2005). Philosophy Faculty Publications. 2.

https://scholarworks.umt.edu/philosophy_pubs/2

This Article is brought to you for free and open access by the Philosophy at ScholarWorks at University of Montana. It has been accepted for inclusion in Philosophy Faculty Publications by an authorized administrator of ScholarWorks at University of Montana. For more information, please contact scholarworks@mso.umt.edu. 


\title{
The Promise and Threat of Nanotechnology
}

\author{
Can Environmental Ethics Guide Us?
}

\author{
Christopher J. Preston
}

\begin{abstract}
The growing presence of the products of nanotechnology in the public domain raises a number of ethical questions. This paper considers whether existing environmental ethics can provide some guidance on these questions. After a brief discussion of the appropriateness of an environmental ethics framework for the task at hand, the paper identifies a representative environmental ethic and uses it to evaluate four salient issues that emerge from nanotechnology. The discussion is intended both to give an initial theoretical take on nanotechnology from the perspective of environmental ethics and to provide a clear indication of the direction from which environmental resistance might come.
\end{abstract}

Keywords: nanotechnology, environmental ethics, nature, fabricated biology, evolution.

\section{Introduction}

In the light of the immense hype and publicity that currently surrounds nanotechnology, it is somewhat surprising that a search of the Center for Environmental Philosophy's bibliography in early 2004 reveals not a single article on nanotechnology by an academic environmental philosopher. ${ }^{1}$ One can loosely speculate why. Perhaps it is that environmental philosophers can be a touch technophobic and little inclined to track the latest scientific developments. They tend to look romantically at what is being lost rather than prospectively at what may be around the next corner. When environmental philosophers do look forward, their bias towards the living world means that they often look towards technologies with the prefix bio- (such as biotechnology) rather those with prefixes such as chemo- or nano-. Whatever its cause, while professional environmental philosophers have stood on the sidelines, nanotechnology has surged into popular and scientific consciousness. According to the Science Citation Index database, the number of research

HYLE - International Journal for Philosophy of Chemistry, Vol. 11 (2005), No. 1, 19-44. Copyright (C) 2005 by HYLE and Christopher J. Preston. 
publications on nanotechnology rose by an average of $27 \%$ per year in the 1990s. The United States government appropriated \$792 million in 2004 for the National Nanotechnology Initiative, indicating that the technology has become a major federal research priority. State and private dollars add considerably to that investment (Greenpeace 2003, pp. 18-20). In popular culture, nanotechnology looms increasingly large, with the screen version of Michael Crichton's novel Prey expected to be released shortly. From Bill McKibben's cautionary tale Enough (McKibben 2003) to front pages stories in the Washington Post $(01 / 31 / 04)$, from the visionary ideas of the Foresight Institute to a $\$ 1.3$ million dollar National Science Foundation funded study of nanotechnology's societal and ethical implications, ${ }^{2}$ from NGO reports on emerging technologies to activist protests in Berkeley, California over the construction of a carbon nanotube factory, there is already a vigorous and contested discourse on what nanotechnology means and what its implications might be for society and for the environment. Professional environmental ethicists need to join this fray and join it fast.

\section{Environmental Ethics as a Suitable Lens}

There can be no doubt that the philosophical issues surrounding the development of nanotechnologies and their products are both interesting and complex. In addition to the numerous technological and scientific issues, nanotechnology raises profound questions in the philosophy of science, the sociology of science, the philosophy of technology, and the philosophy of chemistry. It also poses serious political and ethical questions. Nanotechnology is fairly unique amongst recent technologies in that there do exist efforts to formally address some of these issues. In the United States, early government commitments by the Clinton administration, a reasonably long period of anticipation for the promises of this new technology to actually arrive, and a National Science Foundation sensitized by contentious experiences with genetically modified organisms have combined to create a unique rhetorical space within which the philosophical questions can be investigated.

Included within this emerging discourse are suggestions that nanotechnology is so radical and its disciplinary foundations so unusual that it requires an entirely new ethical framework, one tailor-made for the issues (Khushf 2004). So electric is the buzz around nanotechnology that some of those cognizant of its implications want a completely clean ethical slate for their discussions. Here I argue a different case. The first part of this paper makes the case that the discipline of environmental philosophy already provides a 
particularly suitable framework to bring to bear on many of the pertinent questions.

The ethical issues that are most often brought up in relation to nanotechnologies are almost all issues that have arisen in relation to other environmental promises and threats. Specters such as the threat of biological harm, the danger of runaway replicators, the creation of radically new kinds of materials, the hubris of 'playing God' with natural processes, and the threat to the meaning of being human are all familiar worries raised by previous technological developments such as nuclear power, genetically modified organisms, ecosystem restoration, and human genetic therapies. Environmental philosophy, one might argue, developed specifically in response to these sorts of threats. Optimistic promises by the boosters of nanotechnology such as future material abundance, the end of pollution, and the cessation of extinction are equally familiar to environmental advocates, as is the speculative idea of bringing extinct species back from the dead.

Like nanotechnology, environmental philosophy is inherently interdisciplinary, building bridges between philosophy and ethics on the one hand and ecology, biology, and evolution on the other. This means that environmental philosophy might be readily adapted to perform the cross-disciplinary investigations between chemistry, biology, engineering, and philosophy that nanotechnology demands. Complex ontological questions raised by nanotechnology about the relationship between the natural and the artificial are also firmly within the purview of environmental philosophy and have been discussed by environmental philosophers in relation to biotechnology and genetics. Questions weighted with social rather than environmental dimensions - the fear of creating a socio-economic nano-divide, puzzles about who can patent nanotechnologies, worries about corporate and government abuse, concerns about liability for possible harms caused by nanomaterials are also issues with which environmental ethicists have experience. So while it is clear that nanotechnology promises tremendous technological advancement, it is not so clear that it takes us into completely new ethical terrain. Turning to an existing ethical framework provides an important economy of labor for those addressing the difficult challenges of nanotechnology. It also provides a helpful orienting point in what might otherwise be only lightly charted territory. So while environmental philosophy certainly should not pretend to be the only lens through which to consider the ethical issues that nanotechnology generates, it certainly seems that the discipline might be a proficient guide for many of them.

There is a further consideration at work that makes environmental philosophy a particularly suitable framework to use. This consideration relates to a potent guiding metaphor that frequently slips into the discussion of how to frame nanotechnological endeavor. Nanotechnology is often cast as a way 
for humans to fabricate biological and evolutionary processes. It does this essentially by building from the atom or molecule up. James Van Ehr, CEO of Zyvex, a company dedicated to producing the world's first molecular assemblers, begins his talks on nanotechnology by offering wood and abalone shells as prototypical nanomaterials. ${ }^{3}$ Biology is the proof by example for many nanotechnological dreams. The report on nanotechnology by the U.K.'s Economic and Social Research Council contains the claim that "cell biology offers a proof that at least one kind of nanotechnology is possible" (ESRC 2003, p. 7).

Kevin Yager of the Barrett Research Group at McGill University in Canada similarly opines that "the best proof comes from nature, which has (over the course of billions of years of evolution) created highly sophisticated nanometre-sized devices, including catalysts, motors, data encoding mechanisms, optical sensors, etc." ${ }^{\prime}$ The most audacious proponents of nanotechnology suggest that the implicit aim of the endeavor is for humans to "do better than nature and improve on evolution" (Dinkerlaker 2003). George M. Whitesides laid down this gauntlet in Scientific American remarking that "it would be a marvelous challenge to see if we can outdesign evolution" (Whitesides 2001). Nanotechnology, seen in this light, is a human effort to fabricate biology and to do a better job at it than nature has done. Given this provocative guiding metaphor, it seems probable that a great number of the ethical issues that surround the technology will reside either within environmental philosophy or at its intersection with bioethics.

A final practical reason for considering nanotechnology through an environmental ethics lens has more to do with the way that public perceptions of nanotechnology have been developing than with any proposed theoretical link between the two. It turns out that much of the emerging and anticipated resistance to the development of nanotechnology is coming from the environmental community. Canada's Action Group on Erosion, Technology, and Control (ETC), now calling for a moratorium on the commercial production of nanoparticles until more is known about their toxicity, is the same group that in the past led the fight against genetically modified organisms (ETC 2003). Berkeley's Community Environmental Advisory Committee has spearheaded protests against the construction of a 'molecular foundry' for the production of carbon nanotubes at the Lawrence Berkeley National Laboratory (Artz 2004). Greenpeace U.K. was one of the first to publish a comprehensive discussion paper of the societal implications of nanotechnology (Greenpeace 2003). Whether or not it is in fact the case, nanotechnology is clearly being perceived as a potential environmental threat. Environmentalists are concerned both about the effects of nanomaterials on the biology of individual organisms and about the consequences on local and global ecologies of the widespread dispersion of nanomaterials into the environment. 
Looking at these technologies through an environmental ethics lens will provide a better idea of exactly how these threats are perceived by the communities that are concerned about their development. The first claim of this paper, then, is that while a full discussion of the societal implications of nanotechnology calls upon a diverse range of specialists from across the humanities and the social sciences, the discussion makes particular and targeted demands on the skills of the environmental philosopher.

\section{Selecting an Environmental Ethic}

One immediate problem with the intention to look at nanotechnology through the lens of environmental ethics is that environmental ethics, like nanotechnology, is not a single thing but a diverse and complex cluster of issues, theories, and practices. Different environmental ethicists would approach the promises and threats of nanotechnology in different ways. Some environmental ethicists might adhere to a reverence for life ethic, others to a form of weak anthropocentrism, a third group might orient themselves around an ecosystemic holism, a fourth a deep ecology approach, still others would choose an ethic of care. ${ }^{5}$ It is impossible in one paper to consider how each of these frameworks might apply to nanotechnology. But having pointed out the diversity of positions that environmental ethics offers, it might yet be possible to identify a central environmental intuition that hovers somewhere in the background of many of them. The intention is not to argue for the validity of the chosen intuition here. Such arguments fill many pages of the environmental ethics literature. Rather, the idea is to identify an important ethical principle held by many in the environmental ethics community and then judge how nanotechnology measures up against it.

The one intuition that appears to be common to many environmental positions is the intuition that there is some value associated with historical evolutionary and ecological processes. The process of evolution and the ecologies that have resulted from those processes are believed by many environmental ethicists to possess moral considerability. Since evolution is an open, random, and stochastic process it is necessary to immediately add a scalar modifier to this suggestion. J. Baird Callicott, borrowing much from Aldo Leopold, has suggested in this vein that the primary loci of value in an environmental ethic are evolutionary and ecological processes that occur "at normal spatial and temporal scales" (Callicott 1999, p. 139). If we set aside the difficulty of establishing what 'normal' would mean in this context, the identifiable ethical intuition that remains is that nature deserves moral consideration for its own sake on the basis of the fact that the biotic community 
is the product of millions of years of natural forces that have generated a system that is life supporting, complex, and often diverse.

This central ethical intuition is one that can be found in numerous places in the environmental literature. Aldo Leopold, Holmes Rolston, III, and Robert Elliot provide archetypical articulations. Leopold, for example, states "a thing is right when it tends to preserve the integrity, stability, and beauty of the biotic community, it is wrong when it tends otherwise" (Leopold 1987, pp. 224-5). Rolston claims that "systemic nature is valuable intrinsically, as a projective system $[\ldots]$ for its capacity to throw forward (pro-ject) all the storied natural history" (Rolston 1988, p. 198). Elliot, while trying to explain why environmental restorations are morally suspect, remarks that "we value the forest and river in part because they are representative of the world outside of dominion, because their existence is independent of us" (Elliot 1982, p. 86). Many other examples could be cited. Even distinct environmental orientations such as the ecofeminist ethic of care appear to share some portion of this intuition about the evolutionary process (Preston 2001). In each of these cases, the products of non-human, evolutionary processes are considered to be worthy of some degree of moral consideration. People feel that there is value in the parts of nature that have been created independently of human activity. Other values often championed by environmentalists such as 'wildness', 'beauty', 'spontaneity', 'complexity', and 'ecological integrity' each have direct or indirect connections to this central intuition about the evolutionary process. Exactly how to cash out this value, whether as value that is entirely independent of any valuer, or value that requires a human or non-human valuer to be ascribed, or value that only gains its merit when it functions in human lives in some fashion, has been the subject of vigorous debate in environmental ethics for nearly thirty years. ${ }^{6}$ It is not necessary to go into the nuances of these debates here because, for current purposes, it is relevant only that each of the positions share a common commitment to the significance of the historical evolutionary process. In each case, the historical evolutionary process has a moral significance that is distinct from any of the products of human intentional activity. Choosing the evolutionary process as grounds for environmental value therefore supplies a firm grip on a persistent ethical intuition. It also allows us to work with an intuition that crosses over well from academic theory into policy and public discourse. Even those unfamiliar with environmental ethics often speak about nature as having some ineffable quality possessed by virtue of how it evolved independent of human activity.?

It is important to emphasize that according to this ethical framework the objects in nature that warrant moral concern gain that warrant from being products of a particular creative process deemed to be more important than any features of the products themselves. The capacities possessed by biotic 
nature - capacities such as rationality, sentience, or the ability to photosynthesize - do not themselves earn a natural object moral consideration; it is its relationship to a historical process that creates the bulk of a natural object's value. As the products of natural evolutionary processes, both river valleys and orangutans have natural value, regardless of whether one or the other is sentient (Rolston 1994, Katz 1996).

A second point to note is that temporal realities dictate that this ethic largely excludes any human contributory factor to the value. This is not to deny that humans can on selected occasions contribute to natural values by, for example, carefully managing a prairie through burning and grazing or by restoring a species through captive breeding. Nor is it to deny that humans can create their own kinds of intrinsic values through arts and culture. Rather, these emblematic types of evolutionary ethics simply indicate that environmentalists often have a strong intuition that nature has value in-itself, independent of humans. Nature was operating according to its laws long before humans appeared on the scene. To further emphasize this point, some environmental ethicists assert that it is nature's status as some kind of "radical other" that creates its moral significance (Birch 1990). This observation about the value residing in nature's otherness makes these ethics mostly 'non-anthropocentric'.

Before moving on, it may be necessary to quickly speak to one concern this orientation raises. Some may find the whole starting point objectionable. A large number of people who care about the environment feel that environmental values are always relative to human goods. For these people, it simply does not make any sense to talk about intrinsic natural values in some feature of nature apart from humans. This analysis, for them, seems to start in the wrong place. Furthermore, even those that claim a non-anthropocentric ethic might be concerned about the way the environmental intuition described above seems to look down on any kind of human manipulation of nature. It would be reasonable to object that by choosing the historical evolutionary process as the key value in this environmental ethic, the framework of this paper already begs the question against nanotechnology by looking negatively upon any human manipulation of nature.

While it is true that nature-aside-from-human-manipulation has a major role to play in this ethic, the orientation is not as unhelpful as it may at first seem. It will become clear below that the value of the evolutionary process gives us only a prima facie and defeasible moral obligation towards nature's own creative processes. The value of unmanipulated nature is not an absolute one. After all, every organism must manipulate nature in order to stay alive. And all organisms, including humans, obey the laws of nature at every moment in these manipulations. It cannot be the case then that every human manipulation of non-human nature is wrong. ${ }^{8}$ What this orientation can do 
for us is to set the burden of proof for those that intend to manipulate nature in the place that environmentalists tend to assume it belongs, namely leaning towards the moral value of the historical evolutionary process. While there are a host of problems in determining just how high that burden of proof will be, the intuition about the value of non-humanized and naturally evolved nature is a useful reference point. And in fact, many proponents of nanotechnology may be sympathetic to portions of this ethic. Nanotechnology is often advocated for its potential environmental benefits, benefits such as pollution detection, hazardous waste clean-up, and energy efficiency. Those benefits are often measured in terms of their ability to help us protect the evolutionary and ecological values discussed. Both nano-advocates and those that protest the development of nanotechnology seem often to have the same environmental intuition in mind.

\section{Sampling the Ethical Issues}

The enormous range of nanoproducts envisioned makes any simple ethical judgment about nanotechnology impossible. These products range from tennis balls coated with nano-materials to help them retain their bounce to body armor made from nano-materials to protect soldiers in combat, from nanoparticle coated bandages already used in many hospitals to nanobots that roam the blood stream eliminating undesirables such as cholesterol and cancerous blood cells, from nano-sensors in agricultural fields to detect moisture and the presence of salts to nano-machines that can be spread over toxic waste dumps to neutralize pollution, from nano particles able to deliver targeted drugs in the body to nano-sized interfaces with brain neurons to deliver information directly from computers to the brain. ${ }^{9}$ Making an already murky ethical arena more complex in this case is the difficult task of telling the science fiction apart from the science fact. Also coloring any potential ethical consideration of these products is a tortured history of public policy battles over technologies such as nuclear power, agricultural biotechnology, and human genetic therapies. Despite these complexities it is easy to see that some projected scenarios, for example those of escaped nanobots roaming uncontrolled through native ecosystems, are the environmentalist's worst nightmare. Others, for example the development of highly efficient solar cells and cheap pollution sensors, are the environmentalist's dream.

One strategy adopted in this paper to help simplify the complex ethical terrain is to set aside for the moment a host of issues that are importantly associated with the development of nanotechnologies but are in no way specific to it. These could be loosely categorized as social issues (some of which 
were mentioned above) such as the proprietary rights of those that develop nano-materials, the dangers of creating a socio-economic nano-divide, the legal issue associated with nano tort claims, the separation between scientific nano-elites and the publics that bear the potential costs of the technologies, the privacy issues that nanotechnologies will raise, and associated concerns about personal liberties and freedom of information and opinion. While each of these is an important issue that in some cases is given particular urgency by the development of nanotechnology, there is nothing about these issues that is new or distinctively nano. The frameworks provided by existing and familiar ethical theories that deal with social questions, such as Rawlsian notions of distributive justice or Lockean ideas of natural rights, are as applicable here as elsewhere.

With this attempt to narrow the ethical territory in hand, a useful way to proceed is to select a representative sample of the ethical issues that emerge out of nanotechnology. The following four are chosen primarily for two reasons. The first is that these issues appear to be the ones that have attracted most of the attention of those concerned with the ethics of nanotechnology. The second is that they seem to speak most directly to what is worrying about nanotechnology from the environmentalist's perspective. The four issues are as follows:

1) The creation of radically new types of materials,

2) The uncontrollable replicator problem,

3) The use of nanotechnologies to enhance the human condition, and

4) The projected ability of nanotechnologies to satisfy all human material needs.

These categories are by no means intended to be exhaustive, nor are they mutually exclusive. They do, however, capture a range of the ethical issues that nanotechnology presents. They also lend themselves to the kind of modest initial environmental ethics analysis that is the goal of this paper.

\subsection{The Creation of New Kinds of Materials}

Top-down and bottom-up types of nano-technologies can create materials, structures, and devices of kinds that have never before appeared in nature. There are two types of concern this raises for environmentalists. The first is a somewhat abstract ontological worry about the ethics of creating new, artificial kinds that have never been seen before. The second is the question of whether biological and ecological systems can continue to function in the presence of these new kinds of materials.

The first worry has been raised in an articulate way by Keekok Lee in The Natural and the Artifactual: The Implications of Deep Science and Deep Tech-

nology for Environmental Philosophy. Through a careful discussion of the na- 
ture of artifacts, of Marx's understanding of ourselves as homo faber, and the role of the machine metaphor in human discourse, Lee suggests that the threats to the environment that have hitherto been considered urgent pale into insignificance when placed alongside the threat of artificial kinds produced by nanotechnology. With nanotechnologies, environmentalists have to worry not just about the loss of 'secondary values' such as nature's complexity or its alleged stability, they have to also worry about the loss of 'primary values' such as the very nature of nature as an ontological kind. Nanotechnology, Lee claims, is capable of "turn[ing] biotic and abiotic entities into artifacts" constituting "a radical threat to the ontological category of the natural" (Lee 1999, p. 114). This new threat means that environmental philosophy should orient itself around combating dramatic ontological challenges rather than axiological ones.

There appear to be two reasons why this creation of artificial kinds is a problem for Lee and these reasons can both be traced to the ethical intuition described above. Lee appears to be worried that the replacement of nature with a world of artifacts ("material embodiments of human intentionality") represents a significant ontological loss in itself. Something of considerable intrinsic value has disappeared to be replaced by something of less value. Nanotechnology threatens a diminution of metaphysical kinds by replacing the products of the evolutionary process with something artificial. The second reason, clearly not entirely separable from the first, is that this leaves humanity in an ethically and psychologically impoverished position. Lee contends that systematic elimination of the natural leads to a "narcissistic civilization." The narcissistic civilization created by nanotechnology would no longer have available the "radical otherness" of nature to keep itself in perspective. Lee believes that there is something about the radical alterity of unmodified nature that is important. The independence of nature is an "ontological value" that needs to be preserved in order to maintain an appropriate sense of where humans fit on earth (Lee 1999). A proper sense of ourselves, Lee supposes, is strongly connected to otherness.

The ontological worry that Lee articulates does indeed appear to be a loss. The environmental intuition detailed above values processes and products that are separate from humans. 'Separate' here can mean a couple of different things. Sometimes it will mean valuing organisms that are self-sustaining without human intervention and sometimes it will mean valuing ecosystems that have causal histories independent of any human interference. Environmental ethics will tend to grant a Hereford cow, for example, more moral standing than a car since, unlike the car, the cow is an 'autopoietic' entity or a 'teleological-center-of-a-life' able to sustain itself independently of humans. Similarly, these same ethics will tend to grant the North American bison even more value than the Hereford cow since the bison's causal history does not 
contain human manipulation of the genome in the way that the Hereford cow's does.

Lee finds an analogy to the kind of replacement of nature she is concerned about in Bill McKibben's The End of Nature. In this influential 1989 book, McKibben pointed out how human activity has quickly led to lives lived in a wholly artificial world. According to McKibben, human-caused effects on the atmosphere and global climate have lead to the replacing of nature with an artifact, an artifact that McKibben sometimes calls "Earth 2" (McKibben 1998). Lee presses her argument by claiming that the end of nature to which McKibben drew our attention is less serious than the kind she is worried about with nanotechnology. Human-caused global climate change is not deliberate in the same way as is the creation of new materials through nanotechnology. It is an accidental by-product of human actions. Moreover, Lee points out, climate change threatens something metaphysically different from the threat posed by nanotechnology. What climate change eliminates is nature-unimpacted-by-human-caused-effects ( Nature $\left._{\text {Non-humanized }}\right)$ rather than the nature-constructed-by-natural-processes ( Nature $_{\text {Natural Kind }}$ ) that nanotechnology threatens. Lee insists that the latter is a more significant loss.

While granting that the environmental ethic we are using as a guide will recognize a loss here, it is doubtful that this loss is quite as significant as Lee suggests. One reason to suspect Lee is exaggerating her concern is that while she is certainly right that environmentalists tend to see more value in cows and bison than they do in cars and washing machines, few of them really want to ban cars and washing machines. Neither the creation of artifacts, nor the creation of artificial kinds, seems in itself to ever be enough for environmentalists to talk about prohibitions. If the creation of artificial kinds were itself morally objectionable then synthetic chemists creating over 900,000 new chemical substances a year would receive much more scrutiny from environmentalists than they currently do (Schummer 2001). For the most part, we seem to live alongside artifacts and artificial kinds reasonably well. In some cases, we find artifacts such as paintings and antique wooden furniture especially valuable and appealing. Occasionally we are glad to use artifacts - for example, recycled plastic - to prevent us from destroying more of pristine nature. While many do lament how our lives are increasingly surrounded by artifacts rather than by nature and while others do express some alarm at the activities of synthetic chemists, such resistance hardly amounts to an ethical basis for a prohibition of nanotechnology.

To sustain her case, Lee would have to show two additional things. First, she would have to show that there is something particularly significant about the creation of artifacts at the nanoscale as opposed to the creation of artifacts at the scale of plastic cups, tables and chairs, and climate-changed landscapes. There would have to be something about human intentionality em- 
bodied at the atomic or molecular level that is more morally culpable than human intentionality embodied at the level of tables and chairs. Unfortunately, making this case would seem to involve indicting chemistry and particle physics at the same time, a radical position that would be difficult to maintain if those sciences are to have any merit at all. The second thing she would have to show is that there is a real danger of the products of nanotechnology entirely replacing all natural kinds. Except in the 'grey goo' scenario discussed in Section 4.2 - this does not seem likely. As long as one's ethic still insisted upon the inherent value of the natural kinds produced by evolutionary processes and as long as it ensured that those natural kinds received adequate protection even as more and more artificial kinds were created, Lee's worry about an ontological loss appears to be overstated. An ethic based on the value of the evolutionary process simply does not do enough for a blanket prohibition on all nanotechnologies since there is nothing about nanotechnology that logically entails the total elimination of evolved nature.

The argument from the creation of novel materials, however, has another side to it, one that seems to have considerably more normative force. This is the argument articulated by Canada's ETC Group. The ETC group has called for a moratorium on the production of nanomaterials in the absence of prior testing for health, safety, and environmental impacts (ETC 2003). The ETC group argues that since both human and other parts of biotic nature evolved in environments largely absent of any notable presence of nano-sized particles, extreme caution should be exercised before exposing biotic organisms to these particles. ${ }^{10}$ The unnatural character of nanoparticles, according to ETC, makes them potentially dangerous.

Recent studies have indicated that nano-particles do indeed provide problems for organisms that did not adapt in their presence (Gorman 2002, ETC 2003). Buckminster Fullerenes in water at 500ppb have been discovered to cause brain tissue damage in fish (Oberdörster 2004). Carbon nanotubes washed into the lungs of mice have proved resistant to any natural process of ejection, causing unusual and long-lasting lesions (Lam et al. 2003). Nanotubes also have the ability to make their way into the nucleus of a cell and pharmaceutical companies have known for some time that nanoparticles can cross the blood-brain barrier (Howard \& Maynard 1999, Oberdörster 2003). While many companies are hoping to use these features of nanoparticles to deliver helpful substances into the human body, it seems clear that the potential exists for these processes to cause biological harm. Even if the nanoparticles themselves prove to be mostly benign - something beginning to look increasingly less likely at this point - Vicky Colvin at Rice University has recently shown that known toxins such as PCB's and pesticides can bind to carbon nanotubes and use them as vehicles to hitch a ride into different parts of the body (Colvin 2003). 
Two observations add to the growing sense of alarm. The first is the worrying lack of research on the human and environmental health and safety effects of these new materials. The technologies are so new, and the driving forces behind their development have been so firmly located in the military and the commercial sectors, that health and safety studies have generally been neglected." The National Nanotechnology Initiative devotes only a very small portion of its funds to environmental and biological health studies (ETC 2003, p. 3). The second observation is the fact that there is no regulatory mechanism in place at all at the moment directed specifically towards the unusual mix of quantum and classical properties present at the meso-realm. Regulations are still geared towards familiar macro forms of the material. In the U.S., carbon nanotubes and buckminster fullerenes are currently regulated in the same way as graphite. Given that it is precisely the differences between the properties of the classical and the nanoscale materials that make the latter so interesting, it seems imprudent for the protocols for the different types of materials to be the same. As Eric Drexler of the Foresight Institute, a nano-booster in most areas, points out "You can't simultaneously proclaim a product is new and has all these novel properties and at the same time claim that it can be regulated as if it were nothing different" (Washington Post $2 / 1 / 2004)$.

One quick pause for perspective is appropriate at this point. It is certainly possible to overstate worries about the biological and ecological harm attending non-naturally occurring substances. Our chosen ethic would be unlikely to prohibit all artificial kinds. If fear of the unnatural was an absolute norm then the first time that pieces of wood were fashioned into a table we might have worried about the health effects of tables. It is clear that not all artifacts are harmful simply because humans did not evolve alongside of them and some (such as multi-vitamin pills) are even believed to be beneficial for health under the right circumstances. There is, however, a principled reason for being more cautious about the fabrication of novel nano-materials than about the fabrication of tables and chairs. Past experience with human and environmental health suggests that scale is a relevant factor in determining whether a material will cause harm to a biological system. Inhalation, absorption, diffusion, and transmission across natural barriers have all proven to be vectors for disease and biological harm that depend upon scale. The introduction into the human and natural environment of large numbers of nanoparticles before their biological and dispersion effects are well known does seem to be a cause for concern.

A quick historical comparison is illuminating. The conditions that created the public uproar in Europe over genetically modified organisms (GMOs) seem to be strikingly similar to what is currently going on with nanotechnologies. In the case of GMOs, scientific unknowns over environmental and 
health effects, the lack of an effective regulatory structure, and an unknowing public exposed without their consent by commercial interests combined to generate considerable anger and activism amongst environmentalists. Given the well-established ethical presumption of informed consent before exposing an individual to a possible danger, this resentment appears to have been justified even if it should turn out that the genetically modified crops in question were largely benign. ${ }^{12}$ All of the unsettling factors that motivated resistance to GMOs seem to be in place in the case of the products of nanotechnology. The European Union's Environmental Bureau is seeking to apply to nano-materials the same 'No data, No market' precautionary principle originally developed for their chemical industries. ${ }^{13}$ Given that it is certainly possible there are real risks to human and environmental health created by the newness and scale of nanomaterials, some form of precautionary approach seems appropriate. The ethical value of the evolutionary process at the very least suggests that the burden of proof lies with those seeking to introduce new nanomaterials into the environment rather than with those resisting them.

\subsection{A Brief Dip into the Goo}

Most people who have heard or read anything about nanotechnology have come across the uncontrolled replicator or 'grey goo' problem. It was nanobooster Eric Drexler who first raised the possibility of nanomachines going out of control (Drexler 1986). Drexler pointed out that since molecular manufacturing takes place at such a small scale, large numbers of manufacturing units would have to be working simultaneously on the same project in order to ever create anything useful on the macro-scale. Practical necessity would therefore probably require that such a fabricator be able to reproduce itself. In addition to its ability to reproduce itself and perform its manufacturing tasks, each fabricator would have to be able to solve the problem of directed locomotion in order to be able to procure energy for itself from its environment to complete its tasks. The worry Drexler raised was that a population of such machines left to its own devices could increase in numbers exponentially and consume itself out of an environment. The result would be an environment transformed into a grey goo of nanobots and their waste products. 'Green goo' is an artificially created self-replicating biotic entity that carries the same risk. These possibilities are more technically termed global ecophagy by omnivorous replicators.

Bill Joy, co-founder and chief scientist of Sun Microsystems, suggested in an article in Wired Magazine in 2000 that nanotechnology masks too many dangers for us to allow ourselves to be seduced by it (Joy 2000). He points out that a grey goo scenario could happen by accident or, more worryingly, it 
could happen deliberately. The combination of technologies known as GNR (Genetics, Nanotechnology, and Robotics) is so powerful, Joy warns, that it will "spawn whole new classes of accidents and abuses". Self-replicating nanobots will make possible knowledge enabled mass destruction (KMD), a threat that greatly exceeds any we face today. Joy worries that "we are on the cusp of the further perfection of extreme evil, an evil whose possibility spreads well beyond that which weapons of mass destruction bequeathed to nation states" (Joy 2000).

There are plenty of empirical questions about whether the goo threat is real. Some commentators doubt that we could ever be foolish enough to let loose machines that are able to replicate and nourish themselves. Others suggest that the relatively high energy requirements for such machines preclude their possibility. Drexler himself has recently co-written an article that attempts to dispel the worries that his earlier remarks created (Phoenix \& Drexler 2004). Since one of Phoenix and Drexler's main points about exponential manufacturing is that nobody but a terrorist would purposefully let loose a material that would end up consuming the whole planet - a possibility that they refuse to dismiss - an ethical evaluation of the grey goo problem initially seems likely to follow the same path as any discussion about a powerful technology that has the potential to be used for murderous means. The argument would essentially be that such a technology should not be allowed to fall into the wrong hands. Nevertheless, consideration of what exactly is wrong with self-replicating nanotechnologies in the light of our selected ethic is illuminating.

An uncontrollable, environment-consuming goo is obviously undesirable for reasons of self-interest. This is to say nothing of its lack of aesthetic appeal! But the more interesting moral issue that it raises from an environmental ethics perspective is adroitly anticipated by Joy. Joy states that GNR technologies cross a fundamental line when they allow the "replicating and evolving processes that have been confined to the natural world $[\ldots]$ to become realms of human endeavor" (Joy 2000). If self-locomoting nanobots are able to solve problems and to replicate themselves, then the process of natural selection has been altered. If the fabricators sometimes produce copies of themselves that are not perfect, then they will also be able to evolve. It is this attempt to reproduce the evolutionary process with artificially created replicators and then let this process loose on an unprepared natural environment that is most worrying to the environmental ethicist. The fabricated biology of a nanomachine will now be able to interfere directly with the historical evolutionary process, the very thing that is the basis of the environmental ethic.

The dangers of amending the evolutionary process to serve human ends are many. Some of these problems have already appeared with varying degrees of severity in the case of hybridization of plants and other agricultural 
genetic technologies. The ecological problems of the homogenization of the biotic community, the extinction of wild species, the evolution of more persistent insect pests, and the spread of non-native flora and fauna into native ecosystems have all accompanied previous human interference with the evolutionary process. But each of these existing problems are just pale shadows of the troubles that self-replicating nanomachines could cause.

Self-replicating nano-sized fabricators differ from these other human interferences with the evolutionary process in at least three important ways. The first is biological dissimilarity. The products of agricultural biotechnology are subject to several layers of natural limitation due to their biological similarities to natural products of evolution. Because of its biological similarity, a Hereford cow, for example, is subject to many of the same natural checks and balances as a bison. Left to its own devices, in fact, the Hereford cow will fare considerably poorer in the face of natural forces than the bison. But while a cow bred for milk production and docility is biologically similar to a bison, a nanomachine is absolutely not. The abiotic self-replicating products of nanotechnology will be so dissimilar to anything that has naturally evolved that the chances of there being any natural checks and balances on their populations are slim. The second factor that differentiates previous anthropogenic disruptions to the global ecology from those of nanotechnologies is the issue of ecological niche. When humans introduce species like kudzu, cheatgrass, and zebra mussels into non-native environments these organisms wreak such havoc precisely because there is nothing to check their spread outside of their native ecological niche. Since self-replicating nanotechnologies lack any native ecological niche at all the likelihood of there being any ecological checks on their spread is small. Other than limitations on its energy supply, it is completely unclear what - if any - natural factors will limit the reproductive success of an abiotic nanobot. The third reason that the prospect of self-replicating nanobots differs from the hybridization of flora and fauna has to do with volume. The sheer number of entities that could be produced in a short time by self-replicating nanobots makes this prospect dramatically different from any previously known artificially produced organism. A nanosized particle is one one-hundredthousandth of the diameter of a human hair. This means that the number of nanomachines required to perform any task at the macro level would have to be simply vast. The power of an exponential increase in the number of selfreplicating nano-machines (if they were ever allowed to exist in these kinds of numbers) would be simply staggering. Plagues of rats or locusts would look like trivial biological phenomena by comparison.

Joy's concern about human interference with the process of evolution seems to rest on fairly solid precautionary ground. In Section 4.1 the initial reluctance to fiddle with the products of the evolutionary process turned out 
to be defeasible in the light of the fact that we create many artifacts, even biological ones, that are often not dangerous to us. But problem-solving selfreplicating nanobots co-opt not just biology but also the evolutionary process itself for human ends. This seems to add a whole different level of ethical concern. So regardless of the empirical likelihood of the grey goo scenario ever actually occurring, environmental ethicists seem to be on solid ground to reject any attempt to create them. The central value of the environmental ethic upon which they rely is directly contravened and this provides a good reason to object.

\subsection{Human Enhancement Technologies}

A third area of the application of nanotechnologies that raises concerns for an adherent of our environmental ethic is the area of human enhancement. Ethical questions about enhancements of human health are not uniquely associated with nanotechnology and discussion of this issue is already well developed in the medical ethics literature (Parens 1998, Resnik 2000). But nanotechnologies are likely in the near future to make possible more subtle and effective enhancements including some that will involve dramatic modifications of the human genome. The ability to operate at the scale of telomeres makes possible extending or shortening the life of a cell (Leutwyler 1998, McKibben 2003). The projected creation of microscopic nanobots that can repair cells from the inside or wander through the bloodstream destroying cholesterol and other undesirables promises mark improvements in longevity and quality of life. The technologies being developed for molecular assembly will make direct genetic manipulation easier and cheaper than before. Nanovisionaries believe that these kinds of technologies will dramatically improve health and delay aging. Some even suggest that nanotechnology brings human immortality within reach (Drexler 1986).

In addition to these versions of human enhancement that work with the patient's existing biology, there are other areas of nanotechnology that see the real promise as lying in a new synthesis of the biotic and abiotic. The ability to construct machines with parts that are no bigger than neurons offers the possibility of tying the electrochemical activity of the brain directly into electronic circuits. Significant progress is being made on interfacing biological materials directly with nanomaterials (Webster et al. 2004). The proposed area of research known as Nano-Bio-Info-Cogno (NBIC) combines nano and biological technologies with information technologies and cognitive science. NBIC pursues the goal of human-machine hybrids (or cyborgs) that can outperform existing humans in numerous ways.

The prospect of enhanced cyborgian humans with microelectronic implants that increase their memories or genetic enhancements that increase 
their intelligence has provoked a predictably strong reaction from political and environmental commentators. Francis Fukuyama, addressing mainly the application of traditional biotechnologies to human enhancement has lamented that our 'posthuman' future would be a troubling one in which many of the social and political frameworks that have been successfully developed to accompany our existing concept of human nature would no longer be effective (Fukuyama 2002). Liberal democracies work, Fukuyama believes, because they fit the way we naturally are, a condition that promises to be irrevocably changed by biotechnology. For similar reasons, Bill McKibben more alert than Fukuyama to how nanotechnologies bear on this debate - has asked us to yell a technology-halting "Enough!" to post-humanism through nanotechnology. McKibben makes the case that it is our very mortality and imperfection that makes life meaningful (McKibben 2003). Without death, or with significantly longer lives, or even with some of the more modest enhancements promised by nanotechnicians, McKibben questions how meaning-generating pastimes such as staying physically fit or mentally alert could continue to provide us with the same rewards.

The arguments for and against human enhancement are complex. The fact that many of the enhancements discussed are still squarely in the realm of science fiction makes them harder to think about in a principled way. It is difficult, for example, to reflect on a human future that does not include death. The ethical frameworks that we might use - utilitarianism, rights, autonomy - all seem seriously compromised in certain ways. Nevertheless, there is a range of arguments that can be leveled against human enhancement. Some are social justice arguments that deal with the issue of who will have access to these technologies and who will profit from them. Others are arguments specific to human biology and include concerns about the unknown health effects of human enhancement, worries about the homogenization of the human genome, and arguments like McKibben's about potential loss of meaning given a changing human potential. There is also suspicion of 'playing God' in addition to a simple aesthetic revulsion towards cyborgs.

The first point to note about human enhancement from the perspective of one that values historical evolution is that our existing genetic and biological inheritance is indeed held to be something worth protecting. Our biological inheritance takes the particular form it does as the result of epochs of crafting at the hands of the very natural selective pressures that are valued. It is precisely this history that environmental ethics has identified as being valuable. Aldo Leopold displayed his commitment to the value of this historical lineage when he embraced the sound of a sandhill crane as "a trumpet in the orchestra of evolution" and the crane itself as wearing "a paleontological patent of nobility" (Leopold 1987, pp. 96-7). Others argue that the genetic material inside an organism, perhaps more than the organism itself, is the carrier of 
the evolutionary value because the genome symbolically embodies the evolutionary process. With DNA, Holmes Rolston, III has suggested, "earth gained memory" (Rolston 1988, p. 98). It is the memory of the eons embodied in DNA that makes a token organism valuable. So any alteration to the human genome will be problematic for a person committed to the value of the historical evolutionary process.

However, beyond this initial acknowledgement of the value that organisms and their genomes inherit from their evolutionary past, environmental ethicists will soon find themselves deferring to medical ethicists once they recognize that there are a large number of medical procedures performed on humans today that already tamper with this evolutionary inheritance. In vitro fertilization and other reproductive technologies make it clear that humans do not think it necessary to stick with the evolutionary hand we have been dealt. Commonplace medical technologies such as artificial hips, heart pacemakers, and retinal implants already tinker with our inherited biology and raise the issue of human cyborgs (Haraway 1991). Innoculations and even multivitamin pills demonstrate that we are seldom happy with the functioning of the biological machinery with which we were born. Attempts by medical ethicists to find principled reasons for restricting manipulations of the human body and its genome have met with mixed success. Distinctions such as the one between therapy and enhancement have proven notoriously slippery. Other distinctions based, for example, on the degree of invasiveness of a particular method of treatment or on how much of an original biological process is left intact after treatment have varying degrees of traction. Even in the cases in which useful distinctions are still made, it is clear that there exists no absolute prohibition on anthropogenic manipulations of either the human body as a naturally evolved biological organism or its genome as a representative of a biological kind. Given what is already agreed to be ethically acceptable, the environmental intuition selected above does not appear to contain grounds for a blanket prohibition on human enhancement through nanotechnology.

But this being said, the environmental intuition identified can still provide a helpful orientation to the question of what may or may not be acceptable degrees of manipulation of human biology or the human genome. There is one class of enhancements envisioned by nano-enthusiasts that are distinctive because their advocates seem to have in mind not only the goal of improving human health but also the goal of fundamentally changing what we mean by a human being. The Extropy Institute, for example, interested in the possibility of 'transhumanism', unabashedly claims, "We aim to gradually but firmly change the rules of the game called 'being human'." Their startling mission statement goes on saying that "many of us passively accept or stridently defend the inevitability of human stupidity, malice, conflict, aging, and death 
[...]. The primitive parts of our brain spur us to envy, to hate, to despair, and to kill. Our philosophies and our religions attempt to express our highest values, yet we use them to oppress and control. We use them to crush the world's complexity into a simplicity that we can clutch like a security blanket for the human condition [...]." Their mission statement encourages us not to remain "slaves to our evolutionary history" and invites us to participate in their quest to "connect and cultivate the ingenious and intrepid shapers of the future". ${ }^{14}$

Such a statement illuminates possible grounds for the environmentalist to object to some forms of human enhancement through nanotechnology. If the intention is to use the technology to deliberately divorce humans from our evolutionary and ecological past, then the holder of an environmental ethic that values the evolutionary process can loudly object. The statements of the Extropy Institute are examples of such an intention. It would not be consistent for the environmental ethicist to champion the evolutionary process and then to embrace a post-human future that depended upon departing from this heritage. The chosen environmental intuition therefore provides a reason to be suspicious of manipulations that dramatically change the meaning of what it is to be human. While the line that the environmentalist wishes to draw will likely prove to be fairly fuzzy and tricky to administer, this fuzziness would certainly not be unique amongst the tough questions that reside within medical ethics. Environmental ethics for its own part still wrestles with the question of the degree to which humans are (or should remain) natural beings and so will certainly have a difficult time establishing what is to count as an undesirable departure from our ecological and evolutionary heritage. But at the very least, the commitment to the value of the evolutionary process sets the burden of proof in such a way that it provides a good starting point for the discussion.

\subsection{Projections about Satisfying all Human Needs}

This category is a broad catch-all for many of the promises of the nanoboosters that have escaped mention already. These promises include unarguable benefits such as overcoming material scarcity, eliminating pollution, creating unlimited low cost solar power, ending poverty, curing cancer or the common cold, restoring extinct species, and making available to everyone cheap and powerful computers. Mark Modzelewski, Executive Director of the Nanobusiness Alliance, states confidently "the importance of nanotechnology to the future of mankind cannot be overstated. Nanotech's promise is clean industries, cures for disease, nearly unlimited energy supplies, a continuance of Moore's Law, and perhaps the end of hunger" (Ecologist 2003, p. 36). Others suggest advances in the quality of life comparable to those 
achieved after the industrial revolution (ESRC 2003). One of the reasons for including this broad additional category is to bring attention to the politics of promoting nanotechnology. It is a veritable utopia that the nano-boosters describe.

The first thing that the environmentalist will notice about all these promissory notes is that they have a ring of familiarity to them. Most technological optimists have promised futures in which we would apparently be free to sit on the beach soaking up the sun while the little drudgery left in the workplace was performed by machines. Humans are continually assured by cornucopians that they will soon be freed up to do nothing but pursue art, recreation, and rewarding personal relationships. As has proven to be the case with these previous utopian promises, there is reason to be skeptical about the likelihood of these conditions ever coming about. The promises are made expressly to sell a project or a product. The benefits are touted particularly loudly when the public is getting a hunch that there also might be some risk associated with the product. Electricity too cheap to meter was never a result of nuclear power, nor did its boosters ever think to offer any warnings about the health and safety issues associated with the disposal of nuclear waste. The Pollyanna attitude towards technological futures is often vastly misleading.

Environmentalists that value the historical evolutionary process have particular reasons to see through this kind of talk. Such rhetoric may encourage people to drop their guard with prudential actions that are important today. The promise of electricity too cheap to meter does not encourage energy conservation in the present. The promise of the end of resource scarcity can do nothing but foster the profligate use of currently available resources. Promises to end all pollution and clean up all toxic waste dissuade people from worrying about the messes they are creating today. In each case, existing environmental values such as clean water, intact habitat, and species diversity end up being imperiled by the extreme optimism of the boosters of a technology. Since ecological harms like extinction are not likely to be reversible, it seems prudent to be initially skeptical of the kinds of promissory images that many of the boosters of nanotechnology promulgate.

On the other hand, since the promises and threats of nanotechnology are so multiple and varied, it also seems wise to evaluate them on a case-by-case basis. Better pollution sensors made possible by nanotechnology are hard for environmentalists to reject. Materials made out of carbon nanotubes that are 6 times stronger than steel and 100 times lighter make possible vehicles for transportation that would be vastly more energy efficient than current models. Nanobots that can descend into the depths of contaminated sites and neutralize the pollutants found there are an attractive prospect if safeguards are in place to prevent them from causing additional environmental harm of their own. All of these new technologies would make possible the preserva- 
tion and restoration of habitat, which in turn might enable natural evolutionary processes to continue. In each case, the costs and benefits of a technology should be weighed in much the same fashion as any cost and benefit is weighed; using tried and tested ethical structures to make the calculations. Such calculations demand a sober analysis of the relevant risk in order to be meaningful. Unfortunately, there is normally a bias against doing adequate risk analyses when a product promises great commercial gain. The case of genetically modified crops in the United States is an example of commercial interests rushing a product to market without adequate consideration or even public admission of possible costs. The same thing appears to be happening today with carbon nanotubes. Concerns about the possible toxicity of nanoparticles discussed in Section 4.1 have to remain clearly in view. Serious consideration of where the burden of proof lies will remain important. Doug Parr, chief scientific advisor to Greenpeace UK, reminds us of how easy it is to confuse "no evidence of risk" with "evidence of no risk" (Ecologist 2003, p. 38). The European Union's "no data, no market" policy again seems appropriate.

Nanotechnology comes with both utopian and dystopian visions. In The Arrogance of Humanism David Ehrenfeld pointed out the danger of quasisolutions, solutions that solve one problem while creating several others (Ehrenfeld 1978). Nanotechnology, with such lofty goals and so little known about its effects on biology and ecology, is a fertile arena for generating quasi-solutions. Sometimes it is good to be spurred on by optimistic visions about what a developing technology might do for the human condition. However, environmental ethics can indicate when that vision is becoming distorted. If the vision explicitly includes the goal of fabricating biology and outdesigning evolution, almost all existing environmental ethics will object on both prudential and theoretical grounds. The grey goo scenario is just the most extreme example of a number of dystopian possibilities which, while they need not be used as reasons for abandoning some of the real promises of nanotechnology, should at least be kept in mind alongside the rosy futures outlined by its more enthusiastic advocates.

Those who value the evolutionary process will also always insist that whatever benefits to humankind are promised by nanotechnology, an ethical obligation will remain to continue to protect existing natural diversity. Bald eagles and high deserts, temperate rainforests and two-toed salamanders will all continue to be of inherent value even in the face of whatever technological developments are in the pipeline. Those that value the evolutionary process will continue to advocate their protection. With this in mind, these advocates will likely be moderately skeptical of the most optimistic promissory notes of nanotechnology and be prepared to proceed cautiously with the develop- 
ments that appear capable of delivering the greatest environmental benefits for the least amount of risk.

\section{Conclusion}

There were two goals in this paper. The first was to suggest that environmental ethics supplies an appropriate framework to begin to consider many of the most salient ethical issues surrounding emerging nanotechnologies. The second was to take a representative environmental ethic, one with wide appeal and broad applicability, and to evaluate a number of the most frequently discussed promises of nanotechnology through the lens of this ethic. An environmental ethic that values the evolutionary process proves to offer a number of prima facie reasons to be cautious about many of the promises and threats of nanotechnology. However, because it proves harder than expected to make conceptually clear distinctions between the products of nanotechnologies and those of existing chemical and biological technologies such as plastics and in vitro fertilization, the reasons for caution are often advisory rather than absolutely prohibitive. Only in a few cases do the promises and threats of nanotechnology send up particularly strong red flags. One of these is the case of the introduction of radically new materials into human and natural environments, materials that may prove to be biologically and ecologically harmful. Another is the case of technologies that consciously seek to replicate the process of evolution by natural selection. A third is the prospect of using nanotechnologies to enhance humans away from their inherited evolutionary identity. The latter of these two are occasions in which the developer of the technology seems to be too carried away with the idea of a fabricated biology. The red flags that this behavior raises are likely to provide strong rallying points for activist communities.

The quick evaluation performed here in the light of the selected ethic is in no way intended to exhaust the range of ethical considerations relevant to nanotechnology. There are plenty of additional tests - both environmental and social - that nanotechnologies will have to pass before any of them can be embraced with the kind of enthusiasm of their boosters. But the analysis does provide warnings worth heeding at a time when the environmental community is just beginning its mobilization against the threats of nanotechnology it perceives. 


\section{Acknowledgment}

The author is grateful to Joachim Schummer, Jason Wiener, Lisa Miller, and two anonymous referees for helpful comments and editorial suggestions on earlier drafts of this paper.

\section{Notes}

1 The bibliography is available through the Center for Environmental Philosophy [www.cep.unt.edu]. Lee 1999, which will be discussed below, is a rare example of a monograph in environmental philosophy that specifically discusses nanotechnology.

2 See ${ }^{\text {nano }}$ Science and Technology Studies at the University of South Carolina [nsts.nano.sc.edu].

3 Van Ehr made this claim at his keynote address at the University of South Carolina's "Imaging and Imagining the Nanoscale" conference in Columbia, SC, March 4-7, 2004.

$4 \quad$ See Yager's opinion piece at [www.barrettresearch.ca/teaching/nanotechnology/nano01.htm].

5 For notable contemporary proponents of each of these approaches see Taylor 1986, Norton 1987, Rolston 1988, Drengson \& Inoue 1995, and Warren 2000.

${ }^{6}$ For just a sample of these debates see the special issue of the Monist on intrinsic value (Monist, 75, 1992).

7 The congressional testimony in support of the 1973 U.S. Endangered Species Act is replete with examples of lawmakers trying to find ways to express this intuition.

8 There is a large and complex question lurking beneath this paragraph about whether humans are natural beings and consequently whether human manipulations of nature are natural or unnatural events. I will studiously avoid any attempt to answer this question here. It is one of the hardest questions in environmental ethics. But it is worth noting in this regard that very few people believe that every human action that impacts nature - including detonating nuclear bombs, making tigers extinct, converting forest into parking lots - is as natural as every other.

$9 \quad$ The examples come from a number of sources including The New York Times (11/21/03), The Ecologist (May 2003), Scientific American (September 2001), and No Small Matter II (2003).

10 Exactly how much nanosized material we were exposed to over evolutionary time is unclear. Some natural salts that evaporate from the ocean are nanosized. Some carbon products of combustion are also nanosized. Scientists have recently discovered part of biotic nature they call 'nanomes'. The possible existence of naturally occurring nanobacteria is still under debate (New Scientist, 19 May, 2004).

11 The Center for Biological and Environmental Nanotechnology (CBEN) at Rice University is one of the few research establishments devoted to investigating these health and safety issues.

12 See 'UK Scientists Back GM Maize Crops' at [newsvote.bbc.co.uk/mpapps/pagetools/print/news.bbc.co.uk/1/hi/sci/ tech/3532927.stm]. 
13 See 'EU Chemicals Policy' at [www.eeb.org/activities/chemicals/main.htm].

14 See [www.extropy.org].

\section{References}

Artz, M.: 2004, 'Molecular Foundary Foes Protest Groundbreaking', Berkeley Daily Planet (January) [www.berkeleydaily.org/text/article.cfm? issue =01-30-04\&storyID =18177].

Birch, T: 1990, 'The Incarceration of Wildness: Wilderness Areas as Prisons" Environmental Ethics, 12, 3-26.

Callicott, J.B: 1999, 'Do Deconstructive Ecology and Sociobiology Undermine the Leopold Land Ethic?', in: J.B. Callicott (ed.), Beyond the Land Ethic: More Essays in Environmental Philosophy, State University of New York Press, Albany, pp. 117-139.

Colvin, V: 2003, 'The Potential Environmental Implications of Engineered Nanomaterials', Nature Biotechnology, 21, 1166-1170.

Dinkerlaker, J: 2000, 'Transition to Tomorrow: Social Institutions at the Threshold of Nanotechnology's Molecular Epoch', [www.hpl.hp.com/personal/Jamie_Dinkerlaker]

Drengson, A. \& Inoue, Y. (eds.): 1995, The Deep Ecology Movement: An Introductory Anthology, North Atlantic Publishers, Berkeley.

Drexler, E.: 1986, Engines of Creation, Bantam, New York.

Ecologist: 2003, 'Nanotechnology: A Special Report” 33 (May), 28-44.

Elliot, R: 1982, 'Faking Nature” Inquiry, 25, 81-93.

Economic and Social Research Council (ESRC): 2003, The Social and Economic Challenges of Nanotechnology, [www.esrc.ac.uk/esrccontent/DownloadDocs/Nanotechnology.pdf].

Ehrenfeld, D.: 1978, The Arrogance of Humanism, Oxford UP, New York.

Erosion, Technology, and Control Group (ETC), 2003: 'No Small Matter II: The Case for a Global Moratorium', ETC Group Occasional Paper Series, 7, 1-19, [www.etcgroup.org/documents/Occ.Paper_Nanosafety.pdf].

Fukuyama, F: 2002, Our Posthuman Future, Farrar Strauss and Giroux, New York.

Haraway, D.: 1991, Simians, Cyborgs, and Women: The Reinvention of Nature, Routledge, New York.

Gorman, J.: March 2002, 'Taming Hi-Tech Particles', Science Online, 161, [www.sciencenews.org/articles/20020330/bob8.asp]

Greenpeace: 2003, Future Technologies: Today's Choices: Nanotechnology, Artificial Intelligence and Robotics: A technical, political and institutional map of emerging technologies, [www.greenpeace.org.uk/MultimediaFiles/Live/FullReport/5886.pdf].

Hargrove, E: 1989, Foundations of Environmental Ethics, Prentice Hall, Upper Saddle River.

Howard, C. \& Maynard, R.L. (eds.): 1999, Particulate Matter: Properties and Effects Upon Health, BIOS Scientific Publishers, New York.

Joy, B.: 2000. 'Why the Future Does not Need Us?', Wired Magazine, 8 [www.wired.com/wired/archive/8.04/joy_pr.html].

Katz, E: 1996, Nature as Subject, Rowman and Littlefield, Lanham.

Khushf, G: 2004, 'The ethics of nanotechnology: Vision and values for a new generation of science and engineering', in: The National Academy of Engineering 
(ed.), Emerging Technologies and Ethical Issues in Engineering, National Academies Press, Washington, DC, pp. 29-55.

Lam, C.; James, J.; McCloskey, R. \& Hunter, R.: 2003, 'Pulmonary Toxicity of Single-Wall Carbon Nanotubes in Mice 7 and 90 Days After Intratracheal Instillation', Toxicological Sciences, 77, 126-134 [http://toxsci.oupjournals.org/cgi/content/full/77/1/126].

Lee, K.: 1999, The Natural and the Artifactual: The Implications of Deep Science and Deep Technology for Environmental Philosophy, Lexington Books, Lanham.

Leopold, A.: 1987, A Sand County Almanac: And Sketches here and There, Oxford University Press, New York.

Leutwyler, K.: 1998, 'Turning Back The Strands of Time', Scientific American, (February).

McKibben, B: 1989, The End of Nature, Random House, New York.

McKibben, B.: 1998, 'A Special Moment in History', Atlantic Monthly, 55 (May).

McKibben, B.: 2003, Enough, Henry Holt, New York.

NewScientist.com News Service: 2004, 'Buckyballs Cause Brain Damage in Fish' (March) [www.newscientist.com].

Norton, B.: 1987, Why Preserve Natural Variety? Princeton UP, Princeton.

Oberdörster, G.: 2003, 'Effects and Fate of Inhaled Ultrafine Particles', presentation at the American Chemical Society, New Orleans, LA, 23 March.

Oberdörster, E.: July 2004, 'Manufactured Nanomaterials (Fullerenes, $\mathrm{C}_{60}$ ) Induce Oxidative Stress in the Brain of Juvenile Largemouth Bass" Environmental Health Perspectives, 112 [ehp.niehs.nih.gov/docs/2004/7021/abstract.html].

Parens, E.: 1998, Enbancing Human Traits: Ethical and Social Implications, Georgetown University Press, Washington D.C.

Phoenix, C.; Drexler, E.: 2004, 'Safe Exponential Manufacturing', Nanotechnology, 15, 869-872.

Preston, C.J.: 2001, 'Intrinsic Value and Care: Making Connections Through Ecological Narratives', Environmental Values, 10, 243-263.

Resnik, D.B.: 2000, 'The Moral Significance of the Therapy-Enhancement Distinction in Human Genetics', Cambridge Quarterly in Healthcare Ethics, 9, 365-377.

Rolston, III, H.: 1988, Environmental Ethics: Duties To and Values In the Natural World, Temple University Press, Philadelphia.

Rolston, III, H: 1994, Conserving Natural Value, Columbia UP, New York.

Taylor, P: 1986, Respect for Nature: A Theory of Environmental Ethics, Princeton UP, Princeton

Schummer, J: 2001, 'Ethics of Chemical Synthesis', Hyle, 7, 103-124.

Warren, K: 2000, Ecofeminist Philosophy: A Western Perspective on What it is and Why it Matters, Rowman and Littlefield, Lanham.

Webster, T.; Waid, M.; McKenzie, J.; Price, R. \& Ejiofor, J.: 2004 'Nano-biotechnology: Carbon Nanofibres as Improved Neural and Orthopaedic Implants', Nanotechnology, 15, 48-54.

Whitesides, G. M: 2001, 'The Once and Future Nanomachine.” Scientific American, (September).

Christopher J. Preston:

Department of Philosophy, University of Montana, Missoula, MT 59801, USA;Christopher.Preston@mso.umt.edu 